\title{
Bidding in Common Value Auctions: How the Commercial Construction Industry Corrects for the Winner's Curse
}

\author{
Douglas Dyer • John H. Kagel \\ Dyerwolf Consulting, Crystal Beach, Texas 77650 \\ Department of Economics, University of Pittsburgh, Pittsburgh, Pennsylvania 15260
}

\begin{abstract}
E xperienced construction industry executives suffer from a winner's curse in laboratory common value auction markets (Dyer et al. 1989). This paper identifies essential differences between field environments and the economic theory underlying the laboratory markets that account for the executives' success in the field and a winner's curse in the lab. These are (1) industry-specific mechanisms which enable contractors to escape the winner's curse even when they bid too low, (2) learned, industry-specific evaluative processes which enable experienced contractors to avoid the winner's curse in the first place, and (3) important private value elements that underlie bidding. Also identified are a number of industry-specific bidding characteristics whose evolution can be explained using modern auction theory. Lessons are drawn regarding the use of experimental methods in economics.

(Auctions; Construction Industry; Winner's Curse; Field Data; Experiments)
\end{abstract}

\section{Introduction}

Construction contract bidding is usually treated as a common value auction. In a pure common value auction the value of the item is the same to all bidders. What makes the auction interesting is that bidders have different estimates of the true value at the time they bid. Assuming that bids decrease with decreasing cost estimates, the low bidder faces an adverse selection problem, as he/she wins only when he or she has one of the lowest estimates of the cost of construction. Unless this adverse selection problem is accounted for in bidding, the low bidder is likely to suffer from a "winner's curse," winning the item but making below normal or even negative profits.

Oil companies claim that they fell prey to the winner's curse in early outer continental shelf (OCS) oil lease auctions (Capen et al. 1971, Mead et al. 1983, Gilley et al. 1986). Similar claims have been made in auctions for book publication rights (Dessauer 1981), in professional baseball's free agency market (Cassing and Douglas
1980), and in corporate takeover battles (Roll 1986). The winner's curse has been shown to be a robust phenomenon in laboratory auction markets as well (Bazerman and Samuelson 1983, Kagel and Levin 1986; see Kagel 1995 for a review of laboratory research results).

"Sophisticated" bidders-executives drawn from the commercial construction industry-also suffer from a winner's curse in laboratory auction markets (Dyer et al. 1989). What is more remarkable yet is that these executives suffered from the winner's curse to the same extent as inexperienced student subjects: average losses per auction period were $\$ 1.01$ for the executives versus losses of $\$ 0.37$ per auction for the students (these differences are not statistically significant; predicted profits with risk-neutral Nash equilibrium bidding were over $\$ 5.00$ per auction in both cases). Further, losses in both cases were not simply a matter of bad luck, as over $65 \%$ of the low bids were below the expected value conditional on winning the auction for both subject populations, thereby ensuring negative expected profit in 
over $65 \%$ of all auction periods. Nor did these losses result from overly aggressive bidding on the part of one or two subjects, as $50 \%$ of all bids were below the expected value conditional on winning the auction, so that half of all bids resulted in negative expected profit for both subject populations.

How can experienced, seasoned executives fall prey to a winner's curse in the laboratory but compete successfully and prosper in substantially more complicated field settings? Or to phrase the question the way most biologists and a number of psychologists would: What are the essential differences between the theory underlying laboratory auction market experiments and the natural habitat (field environment) in which these expert bidders developed their skills ("evolved") that caused them to malfunction in the laboratory? We answer this question through follow-up interviews of these executives and others operating in the same market and the analysis of relevant field data.

Two broad conclusions are reached. One is that the executives have learned a set of situation-specific rules of thumb which help them to avoid the winner's curse in the field, but which could not be applied in the laboratory markets. The second is that the bidding environment created in the laboratory and the theory underlying it are not fully representative of the field environment. Rather, the latter has developed escape mechanisms for avoiding the winner's curse that are mutually beneficial to both buyers and sellers and which have not been incorporated into the standard one-shot auction theory literature. In the course of reporting these results we characterize and compare the distribution of bids in the commercial construction industry with outer continental shelf (OCS) oil lease sales, the other auction market commonly characterized as a pure common value auction.

The paper that is closest in spirit to this one is Burns (1985). Both papers share a common motivation: to explain the rather dismal performance of seasoned executives in laboratory auction markets. Both papers identify essential differences between field settings and the theory underlying the experiment that are of central importance to adaptation in the field. An important byproduct of this analysis is the identification of important modeling issues that have been overlooked in the theory. However, whereas Burns studied sequential, pri- vate value English auctions, our paper studies sealed bid, common value offer auctions. Thus, there are important differences between adaptive processes and institutional features of the two markets. In addition, we identify a number of interesting, industry-specific practices and show how modern auction theory literature can explain their evolution.

\section{Bidding Structure, Industry Characteristics, and Sample Data}

Competitive sealed-bid auctions are commonly used in the commercial construction industry. Bids are broken down into a basic bid and bids on alternate plan specifications. The winning bid is determined on the basis of the total bid, including the cost of the alternate conditions adopted. Bids must be submitted by a fixed deadline. The primary difference in bidding on private versus public construction is that there is no announcement of losing bids for private work. In addition, a considerable amount of private sector work, particularly for larger, more unusual jobs, is awarded through "negotiated" contracts.

Jobs that are up for competitive bid are listed in trade publications. These trade publications report the general contractors (GCs), by name, who have purchased the blueprints required to bid a job. Names of subcontractors (SCs) purchasing blueprints are also reported. In some cases bidding is restricted to an approved list of GCs (and sometimes to approved lists of SCs as well). These are contractors who have a track record for completing the work specified beyond satisfying the usual performance bond requirements.

GCs are primarily responsible for lining up SCs and general material supplies and for supervising and coordinating work on the job site. GCs provide minimal direct input into a job so that it is not unusual for $\mathrm{SC}$ and material expenses to total $90 \%$ of the price bid. SCs are responsible for the material expenses associated with their work and may employ other SCs as well.

Table 1 lists the GCs whose top executive officers were interviewed and/or provided us with extensive bid tab sheets (lists of the firm's bid and rivals' bids; bid tabs occasionally contain very illuminating written comments as well). Shown in the table are the gross value of construction contracts and the number of em- 


\begin{tabular}{|c|c|c|c|}
\hline Company Name & Sales & Employment & Activities (SIC code) \\
\hline Marshall Construction & $10 \mathrm{MM}$ & 35 & Commercial \& office building, new construction (1542). \\
\hline Basic Constructors, Inc. & $13 \mathrm{MM}$ & 150 & Waste water \& sewage treatment plant construction (1629). \\
\hline Paisan Construction Co. & $13 \mathrm{MM}$ & 60 & $\begin{array}{l}\text { School building construction; religious building construction, hotel/ } \\
\text { motel \& multi-family home renovation }(1542,1522) \text {. }\end{array}$ \\
\hline Cahaba Construction Co. & $70 \mathrm{MM}$ & 110 & $\begin{array}{l}\text { Commercial \& office building, new construction, renovation and } \\
\text { repair; school \& hospital building construction (1542) }\end{array}$ \\
\hline W. S. Bellows Construction & $100 \mathrm{MM}$ & 300 & Commercial \& office building, new construction (1542). \\
\hline Lott Group, Inc. & $100 \mathrm{MM}$ & 200 & $\begin{array}{l}\text { Commercial \& office building, new construction, renovation \& repair; } \\
\text { hotel/motel new construction }(1542,1522) \text {. }\end{array}$ \\
\hline Spaw-Glass Construction, Inc. & $262 \mathrm{MM}$ & 1200 & $\begin{array}{l}\text { Nonresidential construction; institutional building construction; } \\
\text { industrial building \& warehouses; hotel/motel, new construction; } \\
\text { general contractor, highway \& street construction }(1542,1541 \text {, } \\
1522,1611) \text {. }\end{array}$ \\
\hline
\end{tabular}

Data Source: The Million Dollar Directory Series (Year 1990).

ployees, along with the firm's primary activities (including SIC codes). Although there are no doubt some inconsistencies in the numbers reported, particularly in the relationship between sales and employment, the sales figures accurately capture the range of firm sizes, and the activity list is representative of the work performed. Two of the firms, Spaw-Glass and W. S. Bellows, consistently rank among the top 200 contractors in the United States (as measured by McGraw Hill's ENR reports).

\section{Theoretical Considerations}

The basic theory of discriminatory offer auctions assumes a buyer who purchases a single item from sellers in a one-shot auction. The number $(n)$ of bidders and the probability distribution of bidders' private information are assumed to be common knowledge, with risk neutrality commonly assumed as well. Nature assigns each bidder $i$ a pair of numbers $\left(x_{i}, v_{i}\right)$, where $x_{i}$ is a real valued "signal" observed before $i$ submits a bid, and $v_{i}$ is the construction cost of bidder $i$. If $i$ wins the auction with offer $o\left(x_{i}\right)$, profits are $o\left(x_{i}\right)-v_{i}$. In practice, $x_{i}$ is interpreted as i's sample observation, which is used to establish an initial estimate, $E\left\{v_{i} \mid x_{i}\right\}$, of the cost of the item, with the true cost observed only after the auction.

In a pure common values model $v_{i}$ is the same for all $i$. The main results for common value auctions are due to Milgrom (1979a, b) and Wilson (1977), who assume that signals are conditionally independent and identically distributed, given $v$, with positive density $f(\cdot \mid v)$ (each bidder's signal is an unbiased estimate of $v$ ). However, with symmetry, bidder $i$ wins only when he has the lowest signal value, so that $E\left\{v \mid x_{i}\right\}$ is biased, conditional on the event of winning. This bias can be quite strong. Failure to account for this estimating bias is often referred to as the "winner's curse."

The characteristics of individual offer functions are sensitive to the distributions underlying the signal values and the marginal distribution of $v$. As $n$ increases, two competing forces are at work: strategic factors promote lower offers, but the heightened adverse selection effect promotes higher offers. For a number of distributions the net effect is that the equilibrium bidding strategy first decreases in $n$ and then increases (see Wilson 1992 and Rothkopf 1969). However, under assumptions that hold for most distributions, the expected winning offer decreases in $n$ throughout.

"Money left on the table" - the difference between the low bid and the second lowest bid-is an important indicator of the variance underlying bidders' signal values. It also serves as an immediately available indicator that the winning bidder may have fallen prey to the winner's curse. It too varies with $n$, with the sign depending on the underlying distribution of signal values. 
In the pure private values model $x_{i} \equiv v_{i}$. Here individual offer functions must be decreasing in $n$ as there is no potential winner's curse promoting higher offers. As a consequence the winning offer will be decreasing in $n$ as well. Here too the effect of $n$ on money left on the table depends on the distribution function underlying the signal values.

Table 2 provides numerical illustrations of these effects. The common value auction calculations assume that $v$ is uniformly distributed on the interval $[\underline{v}, \bar{v}]$, with individual bidder signal values, $x_{i}$, uniformly distributed on the interval $[v-\delta, v+\delta]$ (these distributions were used in Dyer et al. 1989). The private value calculations are for an affiliated private value auction in which the $v_{i}$ are uniformly distributed on the interval $\left[v_{o}-\delta, v_{0}+\delta\right]$, with $v_{0}$ uniformly distributed on the interval $[\underline{v}, \bar{v}]$ (the realization of $v_{o}$ is unknown when bids are made). Players in this affiliated private value auction face essentially the same strategic considerations vis-a-vis other players' actions as in the common value auction, only there is no uncertainty about each player's "cost of construction."

The first row reports bid mark-ups as a percentage of $\delta$ required to avoid the winner's curse (these mark-ups are added to individual bidder's signal values). For the pure common value auction, to avoid the winner's curse (break even) requires a substantial mark-up of bids relative to signal values ( $60 \%$ with $n=4,84.6 \%$ with $n$ $=12$ ). In contrast, with affiliated private values, as long as bidders do not bid below their private valuations, they cannot lose money. The second row reports bid mark-ups for the symmetric risk-neutral Nash equilibrium bid function (RNNE) (where, by symmetry, we assume that all bidders employ the same mark-up rule). In the case of common value auctions the two competing forces-bid more as a result of more competition, bid less on account of the winner's curse-just cancel each other out with bidders essentially adding a constant to their cost estimate independent of $n$. In contrast, with affiliated private values the mark-up is decreasing in $n$ throughout, as there is no winner's curse to guard against. In both cases expected profit of the winning bidder is decreasing monotonically in $n$, as is money left on the table.

\section{Bid Distribution Characteristics of Sample Data}

Records of bid distributions on jobs were obtained directly from the firms interviewed. Our data consist of whatever bid tabs we could get from the firms (some firms did not maintain old records) and covers the years 1985-1990. Since only a single bid tab is needed to have complete information for a given job, and many of these firms compete regularly with each other, we also have considerable data for firms that did not maintain old records. Building activity in Houston peaked in the years 1984-85, with a sharp downturn from 1987-1990 (Smith 1992). However, an interim analysis based on bid tabs for the years 1985-86 showed no major differences with our more complete six-year data analysis.

\begin{tabular}{|c|c|c|c|c|c|c|c|}
\hline & \multirow[b]{3}{*}{$n:$} & \multicolumn{6}{|c|}{ Auction Type } \\
\hline & & \multicolumn{3}{|c|}{ Common Value } & \multicolumn{3}{|c|}{ Affiliated Private Value } \\
\hline & & 4 & 7 & 12 & 4 & 7 & 12 \\
\hline Mark-up needed to prevent winner's curse & & $60 \%$ & $75 \%$ & $84.6 \%$ & $0 \%$ & $0 \%$ & $0 \%$ \\
\hline Equilibrium bid mark-up & & $100 \%$ & $100 \%$ & $100 \%$ & $50 \%$ & $28.6 \%$ & $16.7 \%$ \\
\hline Expected Profit & & $40 \%$ & $25 \%$ & $15.4 \%$ & $50 \%$ & $28.6 \%$ & $16.7 \%$ \\
\hline Money left on table & & $10 \%$ & $3.6 \%$ & $1.3 \%$ & $10 \%$ & $3.6 \%$ & $1.3 \%$ \\
\hline
\end{tabular}

Equilibrium bid mark-up and expected profit are approximate as the bid function includes a negative exponential term that diminishes rapidly as $x_{i}$ drops below $\bar{x}-\delta$ (see Dyer et al. 1989 for details). 
We've broken the bid tab data into the five categories in Table 3. Categories were determined on the basis of discussion with GCs indicating that remodeling work involved more uncertainty than new construction, and that remodeling for the Houston Public Housing Authority (HPHA) was subject to more than the usual sort of uncertainties, as they can be very hard to satisfy at times. Private construction is under-represented in the analysis as firms must call rivals to determine their bids or to get rough percentage figures for the distribution of bids from the owner or architect. We included those jobs for which we had reasonably complete bid tabs.

Summary statistics are in Table 3. Listed first is the mean number of bidders by job category (with the standard deviation in parentheses). It averages a high of 8.4 for new construction to a low of 3.2 for the HPHA, and averages between 6-7 in the other three job categories. In contrast, Hendricks et al. (1987) report an average of 3.5 bidders for wildcat OCS leases. Although the uncertainties encountered in bidding for OCS leases are typically orders of magnitude greater than those encountered in these construction contracts, both are commonly treated as canonical examples of common value auctions. As such it is worthwhile comparing the differences, as well as similarities, between bidding in the two markets (also see Keefer 1991 for discussion of standard assumptions underlying winner's curse models that are frequently violated in OCS bidding).

Mean bids are reported next. These range from a high of $\$ 7.9$ million for new public construction to a low of $\$ 0.9$ million in church construction.

Money left on the table is reported in both absolute dollar amount (column 3) and as a percentage of the low bid (columns 4-6). Mean money left on the table ranges from a high of $15.7 \%$ for the HPHA to a low of $2.1 \%$ for new construction in public schools and other public facilities. Note the latter is on jobs with the highest mean bid, $\$ 7.9$ million. Outside of the HPHA, there is simply very little money left on the table as a percentage of the low bid, averaging $7 \%$ or less in all other categories. These data indicate that the underlying distribution of signal values, $x_{i}$, is quite compact, substantially more compact than in OCS leasing where money left on the table averages $50 \%$ of the winning bid for new leases (Hendricks et al. 1987). Only a very tiny part of this difference can be accounted for by the fact that there are fewer bidders, on average, in OCS auctions (on construction jobs with four bidders or less, the typical number in OCS leases, money left on the table averages 6.7\%). Thus, even if commercial construction bidding were a pure common value auction, there is substantially less potential for a winner's curse than in OCS leasing. ${ }^{1}$

The top part of Table 4 reports partial correlation coefficients between major variables by job category. Column 1 shows that, with the exception of the HPHA, money left on the table is inversely related to the number of bidders, with statistical significance achieved in the new public construction job category. These negative correlations are consistent with a number of common distributions for the underlying signal values and the value of the item (recall Table 2). In contrast, for OCS leases, money left on the table is positively related to the number of bidders (Hendricks et al. 1987).

There is no consistent relationship across job categories between the size of the low bid and the number of bidders (column 2), so in general, larger jobs do not attract more bidders. Note the absence of a consistent positive correlation here may be artificial, resulting from more expensive jobs having more restrictive qualified bid lists.

With larger jobs there is more money left on the table, as indicated by the strong positive correlations between money left on the table and the mean bid in all job categories (column 3; statistical significance is achieved in all categories other than HPHA). However, there are consistent negative correlations between money left on the table as a percentage of the low bid and the mean bid (column 4). Similar negative correlations are found in OCS leases (Hendricks et al. 1987).

The bottom part of Table 4 reports several regressions. The first regression shows that money left on the table is positively related to the size of the project (mean bid) and inversely related to the number of bidders (the independent variable employed is $1 / n$ ). The second

\footnotetext{
${ }^{1}$ We focus on money left on the table to measure bid dispersion primarily for ease of comparison with published data from OCS leases. It might be argued that our construction industry measure is biased downward since GCs account for only around $10 \%$ of job cost. However, the GC is fully responsible for SCs completing their work at or below bid.
} 


\begin{tabular}{|c|c|c|c|c|c|c|c|}
\hline Job Categories & $\begin{array}{c}\text { (1) } \\
\text { Mean No. } \\
\text { of Bidders }\end{array}$ & $\begin{array}{c}\text { (2) } \\
\text { Mean Bid }\end{array}$ & $\begin{array}{c}(3) \\
\text { Mean } \\
\left(B_{L+1}-B_{L}\right)\end{array}$ & $\begin{array}{c}\text { (4) } \\
\text { Mean } \\
B_{L+1}-B_{L} \\
B_{L}\end{array}$ & $\begin{array}{c}(5) \\
\text { Min } \\
\frac{B_{L+1}-B_{L}}{B_{L}}\end{array}$ & $\begin{array}{c}(6) \\
\operatorname{Max} \\
\frac{B_{L+1}-B_{L}}{B_{L}}\end{array}$ & $\begin{array}{l}\text { (7) } \\
\text { No. of Jobs } \\
\text { in Sample }\end{array}$ \\
\hline Renovations and Remodeling: Public facilities & $\begin{array}{c}6.7 \\
(3.2)\end{array}$ & $\begin{array}{c}2,424,610 \\
(3,328,764)\end{array}$ & $\begin{array}{c}61,009 \\
(100,499)\end{array}$ & $\begin{array}{c}0.050 \\
(0.081)\end{array}$ & 0.0003 & 0.497 & 53 \\
\hline Churches: New construction and additions & $\begin{array}{c}6.1 \\
(1.9)\end{array}$ & $\begin{array}{c}890,278 \\
(714,324)\end{array}$ & $\begin{array}{c}27,522 \\
(22,667)\end{array}$ & $\begin{array}{c}0.051 \\
(0.056)\end{array}$ & 0.0070 & 0.261 & 29 \\
\hline Remodeling: Houston Housing Authority & $\begin{array}{c}3.2 \\
(1.1)\end{array}$ & $\begin{array}{c}2,565,176 \\
(1,841,593)\end{array}$ & $\begin{array}{c}218,939 \\
(186,279)\end{array}$ & $\begin{array}{c}0.157 \\
(0.108)\end{array}$ & 0.0197 & 0.294 & 5 \\
\hline $\begin{array}{l}\text { New Construction: Public schools and other } \\
\text { public facilities }\end{array}$ & $\begin{array}{c}8.4 \\
(3.4)\end{array}$ & $\begin{array}{c}7,889,030 \\
(8,035,336)\end{array}$ & $\begin{array}{c}138,215 \\
(247,007)\end{array}$ & $\begin{array}{c}0.021 \\
(0.027)\end{array}$ & 0.0000 & 0.222 & 176 \\
\hline Private construction: New and remodeling & $\begin{array}{c}6.0 \\
(2.1)\end{array}$ & $\begin{array}{c}1,928,710 \\
(3,273,194)\end{array}$ & $\begin{array}{c}59,449 \\
(81,223)\end{array}$ & $\begin{array}{c}0.070 \\
(0.083)\end{array}$ & 0.0060 & 0.426 & 32 \\
\hline
\end{tabular}

$B_{L}=$ low bid; $B_{t+1}=$ second-lowest bid.

All bid tab data included had two or more bids. We occasionally (1-2 times) came across a job with a single bid. These contracts were not awarded.

regression shows that money left on the table as a percentage of the low bid is inversely related to the number of bidders $(1 / n)$ as well. Both these conclusions are robust to alternative (linear) specifications and reinforce those reached on the basis of the partial correlation coefficients reported in the top of the table.

The third regression relates the winning offer to the number of bidders $(1 / n)$, using the mean bid on the project as a proxy for the underlying true cost. Controlling for the underlying cost of the item, the winning offer is decreasing in $n$, although it fails to achieve statistical significance at conventional levels ( $t=1.16$, significant at the $p=0.25$ level). Thus, the result is (weakly) consistent with one of the most basic predictions of the auction theory literature.

The last regression relates individual bids to the number of bidders, once again using the mean bid as a proxy for the common underlying cost component. The function is quadratic in $n$ permitting offers to first decrease and then increase as $n$ increases. Although neither coefficient is statistically significant, nor are they significant jointly ( $F=0.30$ ), the coefficient estimates show that individual bids are increasing for all values of $n$ (through $n=23$ ). Thus, the results are closer to the predictions of a common value auction, as private value auctions require reductions in individual bids as $n$ increases.

\section{Differences in Auction Structure Between Theory and Practice}

Although the adverse selection effect may be considerably weaker in the commercial construction industry than in OCS leasing, there is still room for a winner's curse; i.e., winning bidders reevaluating the expected cost of a job on the basis of rivals' bids and regretting winning (bids are announced almost immediately after the bid closing). No respondent used the term "winner's curse," but there are several indications that at least some of the GCs and SCs interviewed are aware of the potential for one. Clear examples of this come from written comments on the bid tabs. For example, one GC, on winning a bid, observed a $6.8 \%$ difference between his bid and the next closest bid on a new construction project, which is a relatively large difference (see Table 3). The GC notes:

\footnotetext{
"Architect sent out addendum instructing all bidders to fill in calendar days at $180[=26$ weeks $]$. We figured a job of this size shouldn't take more than 19 weeks Ithis GC specialized in this type of work.] The others grabbed the 26 week time for general conditions [the GC is directly responsible for these costs]. This would have put us at about $\$ \mathrm{~K}$ thousand dollars [a difference of $2 \%$ from the next lowest bidder, a difference much more in line with average money left on the table]."
}

This same GC, on winning a remodeling job, observed a $7.4 \%$ difference between his bid and the next lowest 


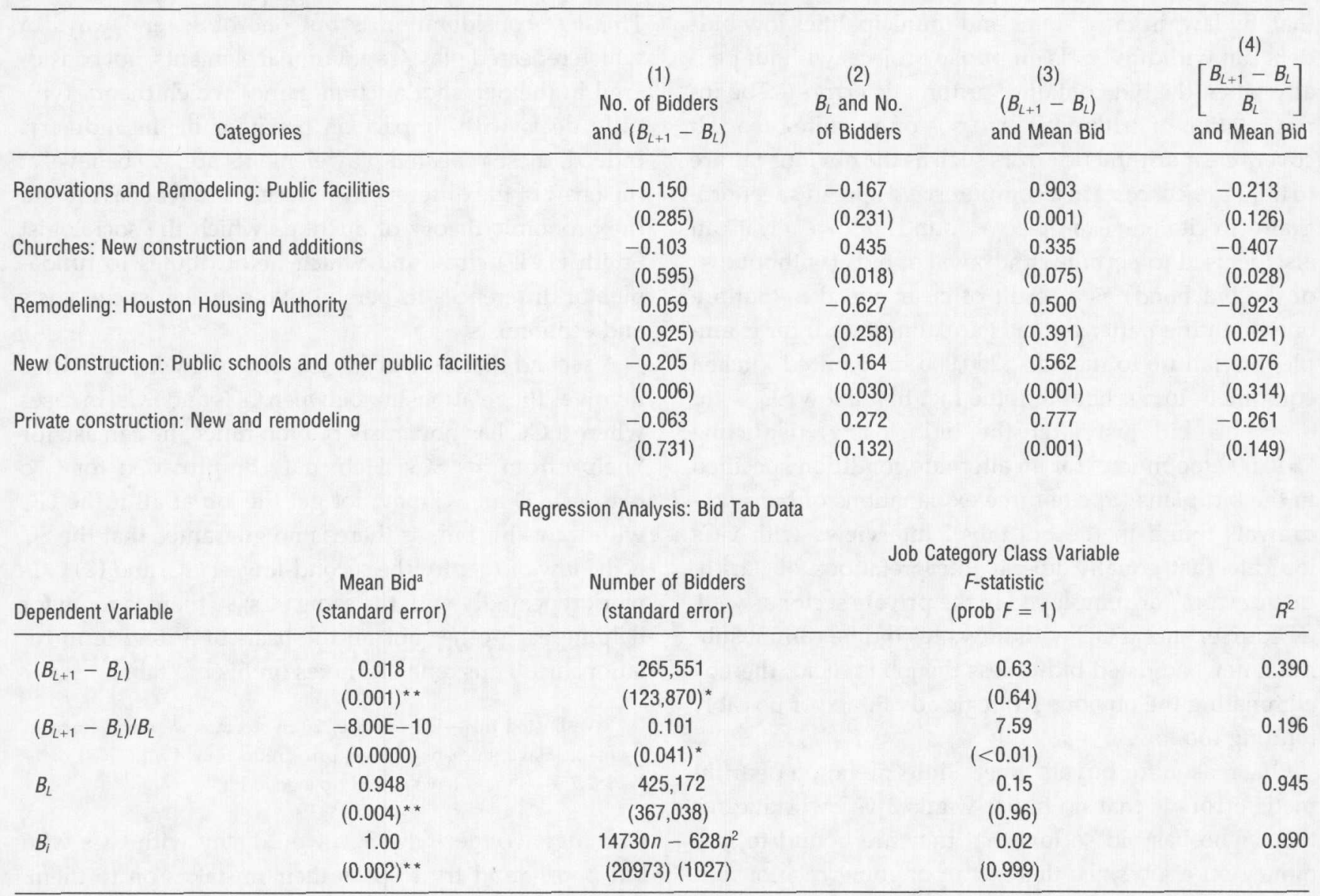

$B_{L}=$ low bid; $B_{L+1}=$ second-lowest bid.

* Significantly different from 0 at $5 \%$ level or better.

** Significantly different from 0 at $1 \%$ level or better.

bid. This is not that unusual for a remodeling job, but still a relatively large difference. The GC notes:

"K. B. at firm C [the next lowest bidder] said he got greedycould have been $\$ K$ thousand dollars Imeaning $C$ could have bid as low as $\$ K$ thousand, where $\$ K$ was below this GC's winning bidl. We're OK."

As shown here and in the previous example, this GC focused on money left on the table as indicative of a potential bidding error. Although money left on the table has no necessary relationship to the existence of a winner's curse, and may simply reflect regret for not having bid higher and earning even more profit, the tone of these remarks clearly indicates concern about having bid too low and losing money as a consequence.

\subsection{Mechanisms for Escaping the Winner's Curse}

Simple survivorship principles suggest that we will not observe systematic overbidding by experienced GCs. However, as remarks on the bid tab sheets indicate (see below), experienced GCs nevertheless do, at times, fall prey to the winner's curse, bidding too little and immediately regretting their bid. In these cases there are at least three mechanisms at their disposal for escaping the winner's curse that are not accounted for in the standard one-shot auction theory literature. 
One mechanism for escaping the winner's curse is that, by law, in most states and municipalities low bidders can withdraw bids on public projects without penalty when the bid contains "arithmetic errors." The interpretation of arithmetic errors is often quite broad. It covers clear arithmetic errors such as the obvious failure to total project costs in a computerized spread sheet program (to cite one example we found). However, it can also be used to permit withdrawal of bids (without loss of the bid bond) as a result of clear mistakes that are only identified after the bids are announced; for example, the failure to include $\$ 250,000$ in required kitchen equipment in a school bid, the fact that a low SC withdrew his bid just after the bid closing, deducting “ $\$ 40,000$ too much" for an alternate condition specified in the bid plans (to cite three explanations of bid withdrawals found in the bid tabs). Interviews with GCs indicate that equally liberal interpretations of "arithmetic errors" are employed in the private sector as well. Of course, once a GC withdraws his bid he cannot submit a new; adjusted bid unless the job is rebid, thereby eliminating the obvious strategic advantage of possibly bidding too low.

One reason for buyers' liberal interpretation of arithmetic errors is that no buyer wants a GC working for them who has bid so low that they are bound to lose money on a job since there is an ongoing relationship between the owner and GC that is necessary for the job's completion. At worst, there is a real potential for the GC going bankrupt, which would have a radical impact on timely completion of the job, resulting in a number of uninsurable expenses. At a minimum, there is likely to be an impact on when the job is completed and the "headaches" associated with the construction. As a result, owners requiring that such bids be lived up to are likely to suffer from a winner's curse of their own. In contrast, these considerations play no role in OCS bidding where the winning bid is determined by the highest cash bonus bid. For an oil company deciding whether it is profitable to undertake the extensive development costs required to produce oil, this bonus bid is a true sunk cost and should have no impact on subsequent development decisions.

Buyers are reluctant to require performance bond forfeiture for bid withdrawals as it can adversely affect the number of bids submitted on subsequent jobs and/or the amount of profit/ cost hedging built into these bids. This last consideration is but one of several ways in which repeated play/reputational elements, not considered in the one-shot auction games which theory typically deals with, impact on behavior in the industry. Indeed, these repeated play elements are, we believe, at the heart of the differences between actual behavior and the economic theory of auctions which the sociologist Smith (1989) cites, and which he attributes to fundamental differences in perspective between sociologists and economists.

A second mechanism for escaping the winner's curse involves the relationship between GCs and SCs. In cases where a GC has obviously bid too much, he can ask for "help" from his SCs. Help may be provided for two reasons: (1) an SC may not get the job at all if the GC withdraws his bid, as there is no guarantee that the SC is the low bidder for the second-lowest GC, and (2) GCs work repeatedly with the same SCs, so there is room for helping each other out on the basis of a long term relationship. Thus, one GC notes on his bid tab:

\footnotetext{
"We busted this-left out $\$ 20,220$ in storm sewers and force main. Have since negotiated price reductions [with SCs] of $\$ 82,757$ - should have picked up a good bit."
}

One may wonder why SCs would stay with GCs who bid poorly and try to pass their mistakes on to them. Clearly, if an SC is squeezed too hard he can walk away from the job. Further, as we argue below, the repeated play interaction between SCs and GCs results in each SC preferring to work with particular GCs and vice versa.

A third mechanism for escaping the winner's curse is found in change orders. Inevitably, situations arise which cause owners to deviate from the original scope of construction called for. The reasons for such changes may be either aesthetic or structural in nature. The price of a change order is a matter of negotiation between the GC and the owner and the architect who acts as the owner's agent. If the GC realizes that he has underbid a job, he is now in a position to at least "cut his losses" through exceptionally tough negotiations. Although the GCs interviewed all agreed that no job should be bid low expecting to make money on change orders, they were frequently mentioned as being particularly profitable. However, this renegotiation process is clearly not 
an open-ended source of increased revenue, given the architect's role as the owner's agent. Finally, although it can be argued that GCs always have an incentive to make as much money as possible on change orders, regardless of the threat of losses, this argument ignores "fairness" considerations players are likely to bring to the game (see, for example, Rabin 1993).

The arithmetic errors and busted bids reported here do not involve the kind of repeated valuation errors by the same individual that economists usually refer to when discussing the winner's curse. As already noted, survivorship principles suggest that we will find few traces of systematic errors by individuals when tracking seasoned GCs. Nevertheless, the "mistakes" identified here are, apparently, endemic to the bidding process, and if not corrected, can wreak havoc on industry outcomes and the fortunes of individual bidders. They are representative of a market level winner's curse, as the competitive bidding process rewards low bidders, which involve proportionately greater numbers of busted bids.

\subsection{Avoiding the Winner's Curse: Situation-specific Learning}

Dyer et al. (1989) conjectured that one reason the construction executives suffered from a winner's curse in laboratory bidding was that they had learned a set of situation-specific rules of thumb which helped them to avoid overbidding in the field, but which could not be applied in the laboratory. Evidence supporting this argument emerged from our interviews as well. An important determinant of the risk associated with bidding a job involves the architect/owner. The architect/owner's reputation for admitting mistakes or ambiguities in construction plans, and their willingness to implement functionally equivalent outcomes using alternative-and cheaper-construction techniques than originally specified, plays an important role in the cost estimates assigned to specific job components and the markup assigned to the total cost estimate (in the experiment, one of the executives jokingly inquired "Who is the architect associated with this job?"). ${ }^{2}$

\footnotetext{
${ }^{2}$ Owners and architects also carry reputations for making change orders, which experienced GCs will use in determining their markup.
}

In addition, firms (or different estimators within a firm) tend to specialize in different types of construction projects. Experienced GCs pride themselves on their familiarity with building different types of structures and figure their estimates to lie within a rather narrow band of the true value. This familiarity is based on past experience. For example, in one bidding session we sat in on, the firm had just completed a similar building by the same architect. When in doubt on the cost estimate to assign to a particular job component, the GC pulled up records from the recently completed job and filled in the missing numbers. ${ }^{3}$ Finally, almost everyone we interviewed had stories about how GCs, unfamiliar with a particular owner or industry, suffered unanticipated losses. Experienced GCs tend to treat these costs as necessary start-up expenses associated with specializing in a new line of construction.

\subsection{Private Value/Chance Elements in Bidding}

Some of the dispersion in bids reported in Table 3 reflect strictly private, rather than common, value elements. It is widely acknowledged within the industry that the amount of profit and / or markup assigned to a bid reflects the opportunity cost of the job. For example, foremen are key personnel in any construction company so that firms are extremely reluctant to let good ones go for lack of work. As such, there is clearly some range of "below normal" profits at which it is better to keep a foreman active than have him stand idle or let go. Although profit and overhead are typically a small component of total cost, given the small spread between bids, small variations can make the difference between winning or losing a contract. Further, it's also possible that the "need" for work plays a role in determining the estimates assigned to different job tasks and the decision to take a chance with less experienced, or less reliable, low-cost SCs.

SC costs constitute the bulk of job expenses for a GC. Variations in SC bids can make the difference between winning or losing a contract. SC costs will differ across GCs for several distinct reasons: an SC may not bid all

\footnotetext{
${ }^{3}$ It's our understanding that oil companies specialize in different geological formations so that they can better apply accumulated past knowledge to interpret seismic records.
} 
GCs, an SC may bid different GCs differently, or a GC may choose not to use a particular SC's bid.

The major source of variation in $\mathrm{SC}^{\prime}$ bids involves failure of a given SC to bid a GC. There are two possible explanations for this. One, which we often heard in interviews, is that SCs will not bid a GC because of past difficulties in working with the GC (reputation effects). This would involve a clear private value element (in addition to such obvious potential sources of friction as timely payment for work completed and the quality standards the SC will be held to, GCs have a large impact on the time it takes to complete a job as they coordinate the work of the SCs). On the other hand, failures to bid a GC may result from the chaotic, last minute submission of SCs' bids (and changes in these bids) that characterize the industry, so that an SC may not get through to all the GCs. To the extent this last element dominates, variation in SCs' bids might best be attributed to pure chance. What is likely is that both factors are at work, with SCs bidding their favorite GCs first and, if time permits, getting through to the rest.

GCs will sometimes not use a low SC's bid because of past difficulties in working with the $\mathrm{SC}$ or because the $\mathrm{SC}$ has no proven track record. Again quoting from the bid tabs:

\footnotetext{
"We used subcontractors who were not low but who we considered to be better qualified for our team. This amounted to a penalty of approximately $\$ 23,000$ [the GC was the second lowest bidder, by $\$ 10,000$, on this $\$ 900,000$ job]. The subs not used were considered either not sufficiently experienced or had performed poorly on previous jobs of ours."
}

GCs sometimes purchase performance bonds for their major SCs which provide some insurance. This insurance is incomplete, however, since nonperformance can result in major coordination problems on a job that increase the GC's costs substantially.

A brief appendix, available from the authors, illustrates variation in SCs' bids and their importance in determining the winning bid.

\section{Industry-specific Characteristics and Their Relationship to Auction Theory}

Bids for a number of subcontracting tasks arrive in a flurry of activity immediately before the bid deadline.
Right up until the moment bids are closed a GC will be working with SCs, confirming the scope of activity associated with the SCs' bids, and accepting/arguing for cuts in the SCs' bids (a member of the GC's bid team will be stationed at the bid site to fill in bid values moments before the bid closing). It is not uncommon for major $\mathrm{SCs}^{\prime}$ bids to arrive within the last 10-20 minutes before the bid closing, resulting in chaotic last minute interactions with SCs.

There appear to be two primary reasons for this flurry of last minute bid activity. One is that SCs (and, in turn, their SCs and suppliers) often do not know the opportunity costs of their bids until bid day, as they are likely to have been bidding on a number of other jobs, and these costs are not fully determined until outcomes of previous bids are known (capacity constraints will affect the size of the mark-up to assign to a particular job). Second, SCs want to avoid having their bids broadcast to other SCs as a target for other SCs to beat. Such "bid shopping" on the part of GCs, although frowned on (particularly by SCs), is probably inherent in the bid process, as it converts a sealed bid auction into a quasiopen (English) auction. And since SCs' costs are affiliated, English auctions are likely to lower the buyer's costs relative to a sealed-bid auction (Milgrom and Weber 1982). This bid shopping problem no doubt affects $\mathrm{SCs}^{\prime}$ suppliers as well, contributing to the last minute flurry of activity. Given the deadline associated with submitting the final sealed bid, SCs have some control over bid shopping by submitting last minute bids. ${ }^{4}$

Negotiations between GCs and SCs often extend beyond the bid deadline as losing SCs contact the GC, or the GC may continue to negotiate with low or favored SCs. Almost everyone we spoke with had stories about how other (unnamed) GCs would bid shop SCs after

\footnotetext{
${ }^{4}$ In response to bid shopping, SCs sometimes form bid depositories, where SCs' bids must be placed several hours before the bid deadline. Sanctions are imposed on GCs and SCs for adjusting these bids. Both the FTC and several (but not all) court cases have declared bid depositories as violations of anti-trust laws (FTC docket \#9183, November, 1985). Although bid depositories primarily involve surplus transfers between GCs and SCs, and between contractors and owners, they also prohibit the winning GC from negotiating with SCs to eliminate duplication in construction activities. This prohibition is likely to reduce economic efficiency.
} 
the bid closing. Such bid shopping is generally considered to have crossed the line between ethical and unethical behavior. However, such bid shopping is likely to take place as the winning GC attempts to discover the overlap in different $\mathrm{SC}$ bids. In doing this the GC may find that the second- or third-lowest SC is indeed the lowest bidder, once the unnecessary duplication has been eliminated.

One particularly striking aspect of these last minute interactions is to observe a GC trying to convince an SC that their bid is too low, that something important has been overlooked in the building specifications. That is, a GC will often work quite hard to help an SC avoid the winner's curse. The incentive for the $G C$ is quite straightforward. In using such a bid the GC faces the prospect of the SC withdrawing his bid after the bid closing, or trying to force an SC to live up to a bid he's very unhappy with, with the same problems an owner faces in forcing a GC to live up to a bid he wants to withdraw. Further, the GC has an interest in not having his rivals employ such a bid, as it may result in his losing the contract, with no assurance that his rival will withdraw his bid once the SC withdraws his bid.

The competitive bidding process, with GCs submitting sealed bids prior to a fixed deadline, is not the only procedure for awarding commercial construction contracts. A considerable amount of private sector work is awarded through negotiated contracts. The term "negotiated contract" covers a variety of practices with differing degrees of competition between rival GCs, but typically involves larger, more unusual jobs where the owner, the architect, and the GC are all involved in working out the scope of the project together (in effect, the GC provides construction engineering services in addition to his building services). There is definitely a competitive element to these contracts, as one respondent whose firm is heavily involved in negotiated work noted:

"What the list [of negotiated jobs won] does not show are the negotiated type projects that we chased but failed to catch."

The more complete disclosure of unusual building characteristics inherent in the negotiated bid process reduces the contingency fees necessary to cover these risks, and results in lower expected costs to owners (see Rothkopf 1969, p. 365).
One common characteristic of these negotiated contracts is that at some point the GC specifies a guaranteed maximum price (GMP), with some arrangement made for the owner and GC to share cost savings below the GMP. ${ }^{5}$ Such cost savings might amount to as much as $5 \%$ of the GMP once the contract is completed. With the GC's involvement in the final building plan specifications and the GMP, negotiated contracts appear to provide a vehicle for risk sharing and quality control on more complicated and specialized building jobs, thereby reducing the scope for a winner's curse on jobs of this sort.

\section{Summary and Conclusions}

Construction contract bidding is usually treated as a common value auction. This paper has identified a number of differences between theoretical and experimental treatments of one-shot common value auctions and practices in the commercial construction industry. Adverse selection problems in the commercial construction industry are considerably smaller than those associated with OCS oil lease bids. Experienced GCs are unlikely to suffer from systematic valuation errors. Nevertheless, there is scope for a market level winner's curse as the competitive bidding process results in busted bids being over-represented among winning bids. Both owners and contractors have an interest in contractors escaping this market level winner's curse, as this can affect the timely delivery and headaches associated with the job (an owner's curse). The net result is that contractors are commonly permitted to withdraw unusually low winning bids without penalty. This mutual interest in escaping the winner's curse extends to $\mathrm{SCs}$, resulting in GCs trying to convince unusually low SCs to withdraw their bids.

There are important repeated play elements to the commercial contracting game. Owners' stringent enforcement of bond forfeiture for withdrawing a winning bid can result in fewer interested bidders in subsequent

\footnotetext{
${ }^{5}$ Interestingly, most negotiated contracts have an important asymmetry with the GC covering all costs above the GMP. Presumably, GCs are more knowledgeable than owners regarding costs, and bear this risk, while owners have assurance regarding the financing costs of the job.
} 
jobs or in bidders who increase their mark-up to account for the added risk. There are private value elements to bidding, too, whose importance is exaggerated because of the compact distribution underlying bids.

At the same time modern auction theory helps explain some peculiar industry characteristics. The flurry of last minute SCs' bids (and cuts in bids) may be explained in part by GCs' efforts (and SCs' counter efforts) to turn a sealed-bid auction into an open (English) auction with its resultant reduction in GCs' costs. More complicated and specialized projects tend to involve negotiated contracts, which may be interpreted as a device for minimizing the risk of a winner's curse, for both owner and contractor, on jobs of this sort.

We draw several lessons from this study about the use of experimental techniques. First, in designing an experiment to test and modify a formal economic theory (which is what our original experiment was designed to do), it is important to recognize that the experimenter implements essential simplifications of the "real world" that are embodied in the theory. In doing this the experimenter may eliminate essential adjustment mechanisms and institutional factors that underlie behavior outside the laboratory. Consequently, to the extent that successful economic behavior involves learning and adaptation to economic contingencies, and learning is situation-specific, performance of economic agents may deteriorate substantially in laboratory compared to field settings (also see Hogarth 1981). Further, to the extent that one discovers seemingly anomalous behavior of the kind that motivated this study, it is essential to look outside the laboratory to discover those institutional factors (if any) that help relieve the problem. For without this, we would not have dreamed of those elements which help relieve the winner's curse in the construction industry. Identifying these industry characteristics may also help pinpoint important modeling issues that have been previously overlooked (see, for example, Harstad and Rothkopf 1992). Finally, in designing experiments intended to have a direct impact on policymaking, unlike experiments designed to test formal economic theories, it is essential for the experimenter to construct an accurate scale model of the target economy. This is, indeed, one of the central principles underlying the design of policy-making experiments in economics (Plott 1987). ${ }^{6}$
"This research was supported by the Sloan Foundation, the Russell Sage Foundation, and the National Science Foundation. We thank the many people in the Houston construction industry who helped with this project: Bill Bain, Bill Baxter, Paul Bell, Ted Connor, Hortense Dyer, George Gillis, Jessie Gonzales, Jeff Holstein, Al Jensen, Dick Lewis, Gene Liggan, Walter Murphy, Jack Marshall, Johnny Meyer, George Miner, John Pollack, Jim Roach, and Cecil Windsor. We thank Susan Garvin and Martha Charepoo for valuable research assistance. We have benefitted from discussions with Doug Davis, Dan Levin, Al Roth, Reinhard Selten, and Jim Smith, from comments on an earlier version of this paper presented at the ESA meetings and the Federal Trade Commission, and the comments of an associate editor of this journal and two referees.

\section{References}

Bazerman, M. H. and W. F. Samuelson, "I Won the Auction But Don't Want the Prize," J. Conflict Resolution, 27 (1983), 618-634.

Burns, P., "Experience and Decision Making: A Comparison of Students and Businessmen in a Simulated Progressive Auction," in V. L. Smith (Ed), Research in Experimental Economics, Volume 3, JAI Press, Greenwich, CT, 1985.

Capen, E. C., R. V. Clapp, and W. M. Campbell, "Competitive Bidding in High-Risk Situations," J. Petrol. Technology, 23 (1971), 641-653.

Cassing, J. and R. W. Douglas, "Implications of the Auction Mechanism in Baseballs' Free Agent Draft," Southern Economic J., 47 (1980), 110-121.

Dessauer, J. P., Book Publishing, Bowker, New York, 1981.

Dyer, D., J. H. Kagel, and D. Levin, "A Comparison of Naive and Experienced Bidders in Common Value Offer Auctions: Laboratory Analysis," Economic J., 99 (1989), 108-115.

FTC, Docket Number 9183, "The Electrical Bid Registration Service of Memphis, Inc.," November 21, 1985.

Harstad, R. M. and M. H. Rothkopf, "Withdrawable Bids as Winner's Curse Insurance," Oper. Res., 43 (1995), 983-994.

Hendricks, K., R. H. Porter, and B. Boudreau, "Information, Returns, and Bidding Behavior in OCS Auctions: 1954-1969," I. Industrial Econ., 35 (1987), 517-542.

Hogarth, R. M., "Beyond Discrete Biases: Functional and Dysfunctional Aspects of Judgmental Heuristics," Psychology Bulletin, 90 (1981), 197-217.

Kagel, J. H., "Auctions: A Survey of Experimental Research," in J. H. Kagel and A. E. Roth (Eds.), The Handbook of Experimental Economics, Princeton University Press, New Jersey, 1995.

- and D. Levin, "The Winner's Curse and Public Information in Common Value Auctions," American Economic Review, 76 (1986), 894-920.

Keefer, D. L., "Resource Allocation Models with Risk Aversion and Probabilistic Dependence: Offshore Oil and Gas Bidding," Management Sci., 37 (1991), 377-395.

Mead, W. J., A. Moseidjord, and P. E. Sorensen, "The Rate of Return Earned by Leases Under Cash Bonus Bidding in OCS Oil and Gas Leases," Energy J., 4 (1983), 37-52.

Milgrom, P. R., The Structure of Information in Competitive Bidding, Garland Publishing, New York, 1979 (a). 
DYER AND KAGEL

Bidding in Common Value Auctions

Milgrom, P. R., "A Convergence Theorem for Competitive Bidding with Differential Information," Econometrica, 49 (1979b), 921-943.

— and R. J. Weber, "A Theory of Auctions and Competitive Bidding," Econometrica, 50 (1982), 1485-1527.

Plott, C. R., "Dimensions of Parallelism: Some Policy Applications of Experimental Methods" in A. E. Roth (Ed.), Laboratory Experimentation in Economics: Six Points of View. Cambridge University Press, 1987.

Rabin, M., "Incorporating Fairness into Game Theory and Economics," American Econ. Rev., 83 (1993), 1281-1303.

Roll, R., "The Hubris Hypothesis of Corporate Takeovers," J. Business, 59 (1986), 197-216.
Rothkopf, M. A., "A Model of Rational Competitive Bidding," Management Sci., 15 (1969), 362-373.

Smith, B. A., "The Fall and Rise of the Houston Real Estate Market," Publication 92-04, Center for Public Policy, University of Houston, Houston, TX, May 1992.

Smith, C. W., Auctions: The Social Construction of Value, Free Press, New York, 1989.

Wilson, R., "A Bidding Model of Perfect Competition," Rev. Econ. Studies, 44 (1977), 511-518.

"Strategic Analysis of Auctions," in R. J. Aumann and S. Hart (Eds.), The Handbook of Game Theory with Economic Applications, Volume 1, Elsevier Science Publishers, Amsterdam, 1992.

Accepted by L. Robin Keller; received December 6, 1994. This paper has been with the authors 3 months for 2 revisions. 